\title{
Non-invasive bedside estimation of nutrition accretion and extracellular water volume in preterm neonates during the first three weeks of life
}

\begin{abstract}
Background: Evaluation of nutrients accretion and body water accumulation is critical but difficult in preterm neonates. There are minimal early postnatal anthropometry data available for this population. The newer sophisticated methods are too complex for routine use

Objective: To perform regional anthropometry and estimate extracellular water volume $(\mathrm{ECW})$ in preterm infants during the first three weeks of life via Harpenden caliper application.

Methods: Mid arm circumference ( MAC), arm fat area (AFA), arm muscle area (AMA), arm area (AA), arm water area (AWA) and extracellular water volume (ECW) were estimated in stable appropriate for gestational age preterm infants born consecutively during a designated study period with a Harpenden's caliper on days of life 10 and 21 under three weight groups: 500-1200g, 1201 to $1800 \mathrm{~g}$ and 1801 to $2500 \mathrm{~g}$. Students t and Kruskal - Wallis ranked tests and univariate regressions were performed for statistical analysis.

Results: A total of 66 data were collected from 42 patients. All anthropometric variables increased transversely on days of life 10 and 21 among all weight groups, whereas, AWA AA decreased. ECW decreased transversely between groups 1 and 3 on DOL 10 and 21 . Highly significant and strong correlations were detected between body weight (BW) and AMA (0.88), BW and AFA (0.78), AFA and tricuspid skin fold thickness at 60seconds of application (TSKF60, 0.85), AMA and MAC (0.86) and AWA and tricuspid skin fold compressibility $(\triangle \mathrm{TSKF}, 0.56)$, yielding regression equations for dependent variables. Extrapolation of AFA and AMA regression lines predicted that fat and muscle tissues are not deposited in human fetus before 400 and $228.4 \mathrm{~g}$ of weight respectively. No side effects of the procedure were noted.

Conclusion: The study presents the regression equations to calculate arm fat, lean body mass and water areas during early postnatal life in the extremely low birth weight and other preterm neonates via a simple bedside procedure, and documents their normative anthropometry reference data for ECW volume and caloric and lean body mass accretion. The extrapolated data reveal that fat and muscle tissues are not deposited in the human fetus before $400 \mathrm{~g}$ and $228.4 \mathrm{~g}$ of body weight.
\end{abstract}

Keywords: preterm neonates, arm fat area, arm muscle area, extracellular water volume, regional anthropometry
Volume 2 Issue I - 2015

\author{
Rita PVerma, Penny London \\ 'Nassau University Medical Center, State University of New \\ York, USA \\ 2Hahnemann University Hospital, USA
}

\begin{abstract}
Correspondence: Rita PVerma, Nassau County University Hospital, Neonatology, Box 30, 2201 Hempstead Turnpike, East Meadow, NY I I554, USA, Tel 5165725050/3319/3318, Email rverma2@numc.edu
\end{abstract}

Received: January 08, 2015 | Published: February 14, 2015
Abbreviations: MAC, mid arm circumference; AFA, arm fat area; AMA, arm muscle area; AA, arm area; AWA, arm water area; ECW, extracellular water volume; BW, body weight; TSKF, tricuspid skin fold; PDA, patent ductus arteriosus; NEC, necrotizing enterocolitis; BPD, bronchopulmonary dysplasia; GA, gestational age; IVH , intraventricular-periventricular hemorrhage; EBM, expressed breast milk

\section{Background}

The assessment of nutrients accretion and extracellular body water accumulation in sick low birth weight neonates is critical but technically difficult to accomplish. ${ }^{1-10}$ Body weight and head circumference, the standard anthropometric measurements for growth do not provide information about the composition of the gained weight. Arm muscle area (AMA) and arm fat area (AFA), regarded as the specific measures of body protein and caloric reserves are determined directly by sophisticated techniques, such as densitometry, isotope-ratio mass spectrometry, calorimetry, total body electrical conductivity, bioelectrical impedance and dual energy X-ray absorptiometry. ${ }^{11}$ These can also be derived from the values of mid arm circumference (MAC) and of subcutaneous tissue thickness of tricuspid or sub scapular skin fold. ${ }^{12}$

Preterm newborn infants have an expanded extracellular water volume (ECW) at birth and a tendency to pathologically accumulate interstitial fluid postnatally. An excess of ECW is correlated with patent ductus arteriosus (PDA), necrotizing enterocolitis (NEC), intraventricular-periventricular hemorrhage and bronchopulmonary dysplasia (BPD). ${ }^{13}$ It also confounds their standard anthropometric measurements for growth. Nutritional inadequacy has been increasingly recognized as a significant risk factor for adverse pulmonary and neuro-developmental outcomes in prematurely born neonates. ${ }^{14,15}$ Most of the nutritional deficiencies are believed to originate during the early weeks of life. ${ }^{16-19}$ Sequential anthropometric assessment of body protein and fat accretion might help in ensuring 
nutritional sufficiency in such infants. There is minimal information regarding nutrition accretion and water accumulation in preterm infants during these crucial early postnatal weeks. Caliper application is a non-invasive and safe bedside procedure whose accuracy for regional anthropometry in preterm infants has been validated. ${ }^{20-22}$

\section{Objective}

Our aim was to estimate the regional anthropometry, as well as the extracellular water volume (ECW) via caliper application in stable preterm infants during the first three critical postnatal weeks of life with advancing chronological and gestational age.

\section{Methodology}

\section{Subjects and Methods}

It was a prospective cohort study. All appropriate for gestational age (AGA) preterm infants with birth weight between 500 and $2500 \mathrm{~g}$ and gestational age (GA) between 23 and 36 completed weeks, who were consecutively admitted to the Neonatal Intensive Care Unit at Hahnemann University Hospital, Philadelphia, Pennsylvania during a designated 6months study period were enrolled. The inclusion criteria mandated physiological stability as per the modified physiological stability index. ${ }^{23}$ Infants with the following conditions were excluded: major congenital/chromosomal anomalies; requirement of $>40 \%$ fractional inspired oxygen or of any modality of positive pressure ventilation; presence of significant cardiac disorder including a clinically significant PDA; renal, hepatic, metabolic or fluid/ electrolytes disorders; intraventricular-periventricular hemorrhage $(\mathrm{IVH})>$ grade 2 ; confirmed or clinically suspected sepsis/meningitis; infants of diabetic or substance abusing mothers and infants taking drugs other than methylxanthines. PDA and IVH were diagnosed as described before. ${ }^{13}$ The infants received either total or partial parenteral nutrition, supplemented with own mothers' expressed breast milk (EBM) or Similac Special Care / Similac formulas ( Ross Laboratories, Columbus, Ohio), prescribed at the discretion of the caretaking medical team. The nutrient contents of formulas were obtained from Ross Laboratories and those of EBM from the data of Gross et al., ${ }^{24}$ The parenteral nutrition information was obtained from the infants' clinical care records. Complications, such as bradycardia, apnea, desaturations and site hematoma were checked for during the procedure.

The cross-sectional and post natal age specific longitudinal studies were done under three birth weight groups: 500 to $1200 \mathrm{~g}, 1201$ to $1800 \mathrm{~g}$ and 1801 to $2500 \mathrm{~g}$. The standard demographics variables, namely sex, race, gestational and chronological age and birth weight were noted. The variables of modified clinical stability index were checked 3days prior to, and on the day of study. Longitudinal data were not collected exclusively in the same infant. All measurements were done in duplicate by a single investigator (PL), the mean value of which was utilized for the study. The study was approved by the institutional review board and informed consents for inclusion in the study were obtained from the legal guardians or parents as applicable before data collection.

\section{Regional Anthropometry}

The following anthropometric variables were measured: body weight, mid-arm circumference (MAC) and triceps and scapular skin-fold thicknesses (TSKF and SSKF). MAC (cm) was measured by using a non-stretch measuring tape applied to the left arm at the mid-point between acromion and tip of olecranon. ${ }^{25}$ Body Weight (g) was measured via SECS745 balance to the nearest $10 \mathrm{~g}$. TSKF and SSKF, expressed in $\mathrm{mm}$, were determined via Harpenden's caliper at exactly $15\left(\mathrm{TSKF}_{15} \& \mathrm{SSF}_{15}\right)$ and 60 seconds $\left(\mathrm{TSKF}_{60}\right.$ and $\mathrm{SSF}_{60}$ ) of application to the nearest $0.1 \mathrm{~mm}$. (Harpenden's Caliper, Harpenden, Healthcheck Systems Inc.) as previously described. ${ }^{26}$ From these measurements the following anthropometric variables were calculated out: Arm Area (AA, expressed in $\mathrm{mm}^{2}$ ), Arm Muscle Area (AMA in $\mathrm{mm}^{2}$ ), Arm Fat Area $\left(\mathrm{AFA}\right.$ in $\mathrm{mm}^{2}$ ) and Arm Water Areas (AWA in $\mathrm{mm}^{2}$ ). The equations provided by Gurney \& Jelliffee ${ }^{27}$ were utilized for this purpose, which were modified to allow for dynamic changes in skin folds as follows: $\mathrm{AA}=\mathrm{MAC}^{2} /$ ил, $\mathrm{AMA}$ $=\left(\mathrm{MAC}-\pi \mathrm{TSKF}_{15}\right)^{2} / 4 \pi, \mathrm{AFA}=\mathrm{AA}-\left(\mathrm{MAC}-\pi \mathrm{TSKF}_{60}\right)^{2} / 4$ л, $\mathrm{AWA}=\mathrm{AA}-\mathrm{AMA}-\mathrm{AFA}$. We further applied the values of TSKF \& SSF compressibility to determine ECW volume. First $\% \Delta$ TSKF was calculated out as follows: $\% \Delta \mathrm{TSKF}=\mathrm{TSKF} 15-\mathrm{TSKF} 60 / \mathrm{TSKF} 15 \mathrm{X}$ 100. Then ECW was estimated by utilizing a regression equation ${ }^{28}$ as follows: $\mathrm{ECW}(\mathrm{ml} / \mathrm{kg})=\% \Delta \mathrm{TSKF}-0.7 / 0.052$. Similar calculations were done for SSF.

\section{Data Analysis}

The groups were compared via Student's t and Kruskal- Wallis ranked tests. Univariate regression analyses were done to assess relationships between body weight and MAC, AMA, AWA and AFA as dependent variables; and between AMA and MAC, AWA and tricuspid skin fold compressibility ( $\triangle \mathrm{TSKF}$ ), AMA and $\mathrm{TSKF}_{15}$ and AFA and $\mathrm{TSKF}_{60}$. A p value $<0.05$ was considered to be significant. The statistical package used for the study was SAS statistical system (SAS Institute Inc, Cary, NC).

\section{Results}

A total of 42 eligible infants were included, out of which seven were $<1200 \mathrm{~g}$ at birth. As some infants underwent repeat studies under different age and weight groups, the number of data collected were higher $(n=66)$ than the number of infants enrolled (Table 1).

Table I Demography and Clinical features of Infants

\begin{tabular}{lll}
\hline $\begin{array}{l}\text { Variables (Total number of } \\
\text { infants=42, total number of } \\
\text { data collected=66) }\end{array}$ & $\begin{array}{l}\text { Day of life } \\
\mathbf{I 0}(\mathbf{n = 3 4})\end{array}$ & $\begin{array}{l}\text { Day of life } \\
\mathbf{2 I}(\mathbf{n}=\mathbf{3 2})\end{array}$ \\
\hline African American $(\%)$ & 88 & 90 \\
Female $(\%)$ & 60 & 62 \\
Birth weight $(\mathrm{g})$ & $1604(168)$ & $1533(147)$ \\
Body Weight on day of study $(\mathrm{g})$ & $1650(191)$ & $1698(174)$ \\
Caloric intake $(\mathrm{kcals} / \mathrm{kg} / \mathrm{d})$ & $81(17.6)$ & $107(11.6)$ \\
Protein intake $(\mathrm{g} / \mathrm{kg} / \mathrm{d})$ & $2.6(0.9)$ & $2.8(0.32)$ \\
Fat intake $(\mathrm{g} / \mathrm{kg} / \mathrm{d})$ & $4.7(\mathrm{I} .8)$ & $5(1.5)$ \\
Carbohydrate $\mathrm{Intake}(\mathrm{g} / \mathrm{d})$ & $12.8(3)$ & $21.3(3.9)$ \\
\hline
\end{tabular}

[Numerical variables expressed as mean (SD)]

The measured and derived anthropometric variables, namely MAC, AMA, AFA, AA and AWA increased significantly on both DOL 10 and 21 among the three weight groups, whereas AWA/AA decreased (Tables $2 \& 3$ ).

In addition, $\% \Delta \mathrm{TSKF}, \% \Delta \mathrm{SSF}$ and $\mathrm{ECW}$ decreased significantly between groups 1 and 3 on DOL 10 and 21, whereas, group 2 did not differ from other groups in this regard. Highly significant and strong correlations were detected between body weight $(\mathrm{BW})$ and AMA (0.88), BW and AFA (0.78), AFA and TSKF60 (0.85), AWA and $\triangle \mathrm{TSKF}(0.56)$ and AMA and MAC (0.86), yielding regression equations to calculate dependent variables (Table 4, Figures 1-3). Upon extrapolation of AFA regression line to the $\mathrm{X}$ intercept where AFA becomes $0 \mathrm{~mm} 2$, we predicted a body weight of $400 \mathrm{~g}$, prior to 
which fat would not be deposited in the fetus. Similar extrapolation of AMA regression line revealed a body weight of $228.4 \mathrm{~g}$ before the deposition of muscle tissue. None of the infants suffered from any adverse effects of the procedure.

Table 2 Anthropometry Data and Calculated ECW according to birth weight on DOL 10

\begin{tabular}{|c|c|c|c|c|}
\hline \multirow[t]{2}{*}{ Variables } & \multirow{2}{*}{$\begin{array}{l}\text { BW < } \\
\text { I } 200 \mathrm{~g} \\
(\mathrm{n}=7)\end{array}$} & \multirow{2}{*}{$\begin{array}{l}\text { BW } \\
|20|-\mid 800 \mathrm{~g} \\
(n=33)\end{array}$} & \multirow{2}{*}{$\begin{array}{l}\text { BW } \\
1801-2500 \mathrm{~g} \\
(n=26)\end{array}$} & \multirow[t]{2}{*}{$\begin{array}{l}\text { Significant } \\
\text { p values }\end{array}$} \\
\hline & & & & \\
\hline MAC (mm) & $60(7)$ & $79(6)$ & $90(6)$ & $a, b, c$ \\
\hline TSKF60(mm) & $2.1(0.3)$ & $2.9(0.4)$ & $3(0.48)$ & $a, c$ \\
\hline$\% \Delta \mathrm{TSKF}$ & $20.9(3.9)$ & $17.3(4.2)$ & $15.6(4.1)$ & c \\
\hline SSFM60(mm) & $2(0.5)$ & $2.8(0.5)$ & $3.3(0.3)$ & $a, b, c$ \\
\hline$\% \Delta S S F$ & 19.3(4) & $17(4)$ & 14.4(4) & $b, c$ \\
\hline $\mathrm{AA}(\mathrm{mm} 2)$ & $280.3(70)$ & $483.7(87.7)$ & $644.2(99)$ & $a, b, c$ \\
\hline AWA (mm2) & $16.4(7.6)$ & $21.9(6.2)$ & $23.5(4.7)$ & $a, c$ \\
\hline AWA/AA (\%) & $5.8(1.4)$ & $4.5(I . I)$ & $3.8(1)$ & $a, b, c$ \\
\hline $\mathrm{AMA}(\mathrm{mm} 2)$ & $206.6(55.6)$ & $364.8(70.3)$ & $492.3(79.3)$ & $a, b, c$ \\
\hline AFA $(m m 2)$ & $57.1(11.4)$ & $102.4(24.3)$ & $128.2(24.8)$ & $a, b, c$ \\
\hline $\begin{array}{l}\text { Calculated } \\
\text { ECW (ml/kg) }\end{array}$ & $43 I(62)$ & $386(119)$ & $339(87)$ & c \\
\hline
\end{tabular}

Data are presented as mean (standard deviation); $a=p<0.05$ for group I vs $2, b=p<0.05$ for group 2 vs. 3 and $c=p<0.05$ for group I vs.3. All significant $p$ values are $<0.02$

Table 3 Anthropometry Data and Calculated ECW according to birth weight on Day of life 21

\begin{tabular}{|c|c|c|c|c|}
\hline Variables & $\begin{array}{l}\text { BW < } \\
1200 \mathrm{~g} \\
(n=7)\end{array}$ & $\begin{array}{l}\text { BW } \\
|20|- \\
\mid 800 \mathrm{~g} \\
(\mathrm{n}=33)\end{array}$ & $\begin{array}{l}\text { BW } \\
|80|-2500 \mathrm{~g} \\
(n=26)\end{array}$ & $\begin{array}{l}\text { Significant } \\
\text { p values }\end{array}$ \\
\hline $\mathrm{MAC}(\mathrm{mm})$ & $66(5.1)$ & $76.8(6.9)$ & $94.2(6.6)$ & $a, b, c$ \\
\hline TSKF60 $(\mathrm{mm})$ & $2.38(0.2)$ & $3.12(0.5)$ & $3.52(0.4)$ & $a, c$ \\
\hline$\% \Delta \mathrm{TSKF}$ & $21.5(4.4)$ & I7.4(4.8) & $\mid 4.8(2.5)$ & c \\
\hline $\mathrm{SSF} 60(\mathrm{~mm})$ & $2.3(0.2)$ & $3(0.05)$ & $3.7(0.3 \mathrm{I})$ & $a, b, c$ \\
\hline$\% \Delta S S F$ & $20.8(5.6)$ & I3.6(4.5) & $13(2.8)$ & $\mathrm{a}, \mathrm{c}$ \\
\hline $\mathrm{AA}(\mathrm{mm} 2)$ & $324.2(32.7)$ & $472.4(88.8)$ & $713.4(108.5)$ & $a, b, c$ \\
\hline $\mathrm{AWA}(\mathrm{mm} 2)$ & I3.I(8.2) & $21.2(6.6)$ & $23.6(7.5)$ & $\mathrm{a}, \mathrm{c}$ \\
\hline AWA/AA(\%) & 4.I (2.5) & $4.5(1.2)$ & $3.3(0.8)$ & $b$ \\
\hline $\mathrm{AMA}(\mathrm{mm} 2)$ & $239.6(26.8)$ & $34 I(78.1)$ & $533.2(99.7)$ & $a, b, c$ \\
\hline $\mathrm{AFA}(\mathrm{mm} 2)$ & $71.5(10.4)$ & $110.2(2 I)$ & I56.6(24.3) & $a, b, c$ \\
\hline $\begin{array}{l}\text { Calculated } \\
\mathrm{ECW}(\mathrm{ml} / \mathrm{kg})\end{array}$ & $443(113)$ & $379(115)$ & $287(63)$ & c \\
\hline
\end{tabular}

Data are presented as mean (standard deviation); $a=p<0.05$ for group Ivs. 2 , $b=p<0.05$ for group 2 vs. 3 and $c=p<0.05$ for group I vs, 3. All significant $P$ values are $<0.004$

Table 4 Significant correlations \& regression equations

\begin{tabular}{|c|c|c|c|}
\hline Variables & r2 & $\mathbf{p}$ & prediction equation \\
\hline AMA \& Body & 0.88 & $<0.00001$ & AMA $=0.235 \times$ weight - \\
\hline AFA \& BW & 0.78 & $<0.00001$ & $\mathrm{AFA}=6.4883+0.059 \times$ weight \\
\hline AWA \& $\triangle T S K F$ & 0.58 & $<0.0001$ & $\begin{array}{l}\text { AWA }=10.375+16.587 \times \\
\Delta \text { TSKF }\end{array}$ \\
\hline AFA \& TSKF60 & 0.85 & $<0.0001$ & $\begin{array}{l}\mathrm{AFA}=48.945 \times \mathrm{TSKF} 60- \\
34.614\end{array}$ \\
\hline AMA \& MAC & 0.86 & $<0.00001$ & $\begin{array}{l}A M A=7.88338 \times M A C- \\
252.967\end{array}$ \\
\hline AMA \& TSKFI5 & 0.5 & $<0.008$ & $\begin{array}{l}\mathrm{AMA}=86.439+80.439 \\
\text { X TSKFI5 }\end{array}$ \\
\hline
\end{tabular}

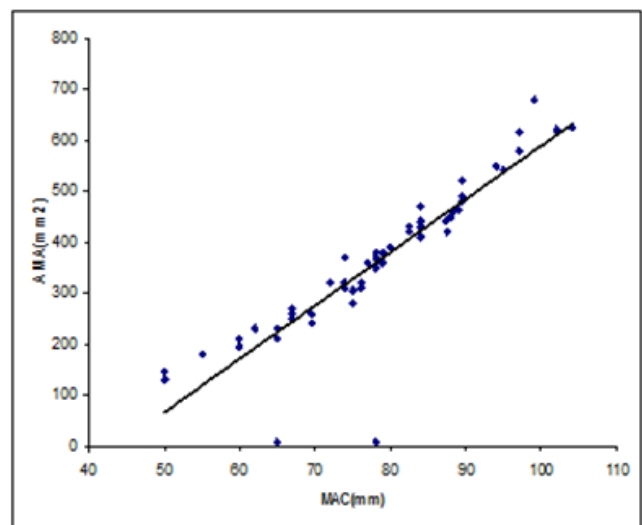

Figure I Scatter gram and Regression of AMA and MAC. Some points are superimposed.

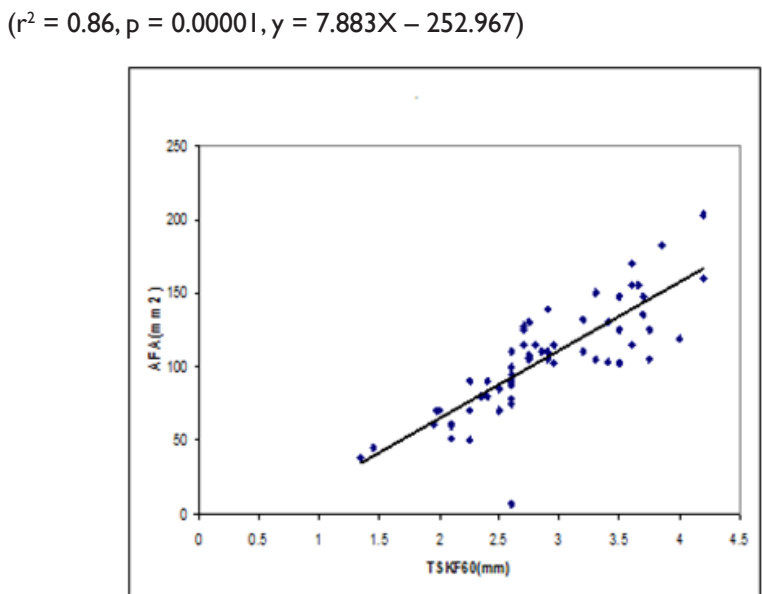

Figure 2 Scattergram and Regression of AFA and TSKF60. Some points are superimposed.

$\left(r^{2}=0.85, p=0.000 I, y=48.945 X-34.614\right)$

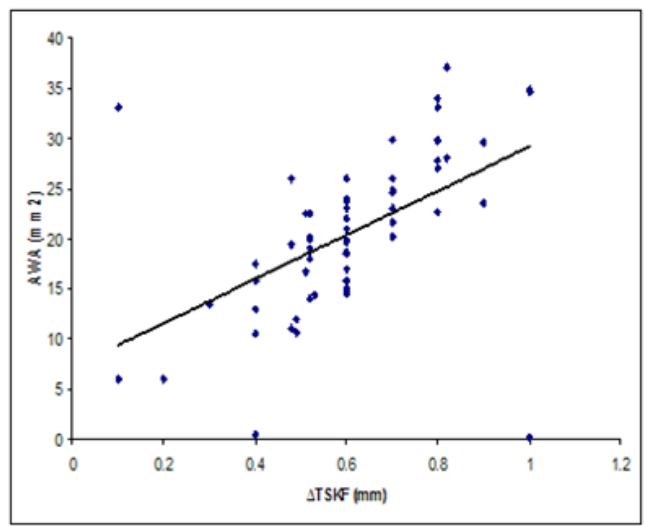

Figure 3 Scattergram and Regression of AWA and $\Delta$ TSKF. Some points are superimposed.

$$
\left(r^{2}=0.58, p=0.0001, y=10.375+16.587 X\right)
$$

\section{Discussion}

Sequential reference data for regional anthropometry in preterm neonates are scant. Georgieff et al., ${ }^{6}$ measured AFA and AMA in 22 preterm infants with a mean birth weight of $1640 \mathrm{~g}$ and mean gestational age of 31 weeks during the first 4 weeks of life by using 
Harpenden's caliper. They did not specify inclusion of the extremely low birth weight infants. This is the first study that has sequentially predicted these variables, as well as ECW volume utilizing this procedure during the first three critical weeks of life in preterm infants, and has specifically reported on the extremely low birth weight neonates. The accuracy of caliper application for regional anthropometry in preterm infants has been validated. ${ }^{20-22}$ Sheng et al., ${ }^{2}$ studied total fat mass by dilution of isotope water and concluded that subscapular skin fold thickness is the best predictor of total fat mass $(r=0.78)$ and an appropriate choice for estimating fat deposition in preterm infants. Koo et al., ${ }^{21}$ compared measured and derived anthropometry for the prediction of body composition by utilizing magnetic resonance imaging and caliper application in a cohort of preterm appropriate-for-gestational-age neonates and concluded that both are accurate predictors of regional body composition. They determined body composition by DXA scan, whose use in small infants has been validated independently by multiple investigators. ${ }^{29,30}$ They demonstrated that the measured and derived anthropometry from mid arm circumference and triceps skin fold thickness offers the maximum predictive value for body composition, and arm muscle and fat areas are the most important derived anthropometry in the prediction of body composition in neonates. Dung et al demonstrated that in preterm neonates, weight is a more effective predictor of fat free mass than impedance index and recommended a bedside procedure for its estimation based on anthropometric parameters rather than bioelectric impedance analysis. ${ }^{31}$

Our strong, linear and highly significant correlations between anthropometric variables are consistent with those reports which utilized sophisticated methodologies to derive them. ${ }^{7,8,21}$ These studies however, were done primarily on late preterm or mostly term infants. Rigo et al performed anthropometry by dual energy X-ray absorptiometry and documented correlations between body weight and lean body mass and fat mass to be 0.9 and 0.8 respectively, which are consistent with our values. ${ }^{8}$ Lapillonne et al performed dual-energy x-ray absorptiometry in 70 infants with gestational age between 32 to 41 weeks and showed correlations with birth weight to be 0.91 for body fat and 0.97 for lean mass during the first $48 \mathrm{hrs}$ of life. ${ }^{7}$ Similar results were documented by Koo et al who compared body composition derived by dual energy $\mathrm{X}$ - ray absorptiometry and caliper application..$^{21}$ They found that skin fold thickness obtained by caliper application had a correlation of $0.9 \%$ with muscle and fat areas as measured by DXA scan. Excler et al studied documented regression values for MAC and birth weight in term infants which are comparable to our results. ${ }^{20}$ According to our regression equations, as well as to those from other investigators, arm fat area is predicted by body weight and tricuspid skin fold thickness at 60seconds of application; and arm muscle area by body weight, mid arm circumference and tricuspid skin fold thickness at 15 seconds of application. ${ }^{32-34}$ The multiple regression analysis of our results allows the detection of the best discriminant parameters for anthropometric prediction. We found MAC and body weight to be the best predictors for AMA, and TSKF 60 a better predictor for AFA than body weight. These observations are in accordance with other studies which utilized direct methods. ${ }^{7,21}$ Applying our regression equation we extrapolated that fat and lean tissues would not be deposited in the fetus before attaining the body weight of $400 \mathrm{~g}$ and $228.4 \mathrm{~g}$ respectively. This is consistent with the reports on fetal body composition ${ }^{35,36}$ We could not compare the extrapolated body weight for AMA, as the authors reported fetal total body protein content and not the lean muscle mass.

The calculated volume of ECW in our study is consistent with previous reports..$^{1,334-37}$ Bauer et al., ${ }^{1}$ estimated ECW by sucrose dilution in $<1500 \mathrm{~g}$ infants to be $425+46 \mathrm{ml} / \mathrm{kg}$ during first week of life which is in accordance with our results. Similar results were obtained by Heimler $(504+14 \mathrm{ml} / \mathrm{kg})^{3}$ Shaffer $(410+20 \mathrm{ml} / \mathrm{kg}),{ }^{37}$ and Hartnoll $(505+35 \mathrm{ml} / \mathrm{kg})^{36}$ who determined ECW by bromide dilution in infants between 25-32weeks gestation during the first week of life. We found that arm water area increased directly with intrauterine and postnatal maturation, whereas its ratio with total arm area declined. This pattern follows the reported body water homeostasis of growing preterm infants. It has been documented that total body water increases exponentially with growth and new tissue deposition, whereas, the ratio of solids and water, as well as the volume of extracellular water decrease. ${ }^{38,39}$

Unlike Georgieff et al., ${ }^{6}$ who used gestational age for anthropometric analysis, we used body weight to predict arm muscle and fat areas. Investigators have shown that body fat and lean mass correlate more strongly with body weight than gestational age. ${ }^{7}$ Excler et al reported that MAC and AFA correlate strongly with birth weight in term infants. ${ }^{20}$ We have documented such results in preterm infants. We studied the infants on DOLs 10 and 21, as the assessed mean day of life on which birth weight is reached after the physiological weight loss in preterm infants is $10^{14,40}$ and by DOL 21 most of the initial acute clinical- pathological conditions are either resolved or stabilized. The majority of infants in our study were of African American ethnicity and that is a valid criticism as ethnic variability has been reported in morbidities seen in preterm neonates and could be a factor in anthropometry as well. The AMA and MAC both dropped marginally and non-significantly in the weight group of 1201 to $1800 \mathrm{~g}$ between DOLs 10 and 21 unlike other weight groups, whereas, AFA increased consistently. It could be attributed to the low protein intake during the period of transition from parenteral to enteral nutrition in this weight group. A mean intake of $2.8 \mathrm{~g} / \mathrm{kg} / \mathrm{d}$ of protein has been shown to provide comparable or even higher weight gain and nitrogen retention to intrauterine growth rates and acceptable plasma concentrations of transthyretin and albumin, which are markers for appropriate metabolic response. ${ }^{41,42}$ The ESPGHAN guidelines have commented that a protein intake of approximately $3 \mathrm{gm} / \mathrm{kg} / \mathrm{d}$ matches the intrauterine growth in preterm infants, which can be maintained with a $<3 \mathrm{gm} / \mathrm{kg} / \mathrm{d}$ intake as well, if the total caloric supply is comparable. ${ }^{43}$ It has been documented that protein intakes in excess of $3 \mathrm{gm} / 100 \mathrm{kcal}$ is not utilized completely. ${ }^{42}$ To attain a suggested supplementation of protein of $3.5-4.5 \mathrm{~g} / \mathrm{kg} / \mathrm{d}$ by day of life 10 is difficult in clinical settings due to associated complications, such as metabolic acidosis, especially in the extremely low birth weight infants. Georgieff et al., ${ }^{6}$ have shown that the major determinants of fat and protein accretion during the first four weeks of life are energy intake and not the protein or fat intakes.

The newer and more sophisticated methods for neonatal anthropometry, although precise, are complex, expensive and risky which limits their routine or widespread use in clinical practice. Bedside caliper application is a non-invasive, simple, practical and inexpensive procedure. The consistencies of our data with those from direct studies suggest our results to be accurate and credible. Our normative data and equations could be utilized in clinical practice to assess and manage growth failure in sick preterm infants. They could also be applied in nutritional trials to evaluate nutrient accretion and the composition of the gained weight. The assessment of ECW, and thereby its optimization with the help of this bedside procedure might result in reducing the incidence of morbidities associated with excess ECW accumulation.

\section{Acknowledgements}

None. 


\section{Conflicts of interest}

Author declares there are no conflicts of interest.

\section{Funding}

None.

\section{References}

1. Bauer K, Versmold HT, Proiss A, et al. Body composition, nutrition, and fluid balance during the first two weeks of life in preterm neonates weighing less than 1500 grams. J pediatr. 1991;118(4 Pt 1):615-620.

2. Sheng HP, Muthappa PB, Wong WW, et al. Pitfalls of body fat assessments in premature infants by anthropometry. Biol Neonate. 1993;64(5):279-286.

3. Heimler R, Doumas BT, Jendrzejczak BM, et al. Relationship between nutrition, weight change and fluid compartments in preterm infants during the first week of life. J Pediatr. 1993;122(1):110-114.

4. Wauben IP, Atkinson SA, Shah JK, et al. Growth and body composition of preterm infants: influence of nutrient fortification of mother's milk in hospital and breastfeeding post-hospital discharge. Acta Paediatr. 1998;87(7):780-785.

5. Raghavan CV, Super DM, Chatburn RL, et al. Estimation of total body water in very low birth weight infants by using anthropometry with and without bioelectrical impedance and $\mathrm{H} 2$ [(18)O]. Am J Clin Nutr . 1998;68(3):668-674.

6. Georgieff MK, Amarnath UM, Mills MM. Determinants of arm muscle and fat accretion during the first postnatal month in preterm newborn infants. J Pediatr Gastroenterol Nutr. 1989;9(2):219-224.

7. Lapillonne A, Baillon $\mathrm{P}$, Claris $\mathrm{O}$, et al. Body composition in appropriate and in small for gestational age infants. Acta pediatr. 1997;86(2):196-200

8. Rigo J, Nyamugabo K, Picaud JC, et al. Reference Values of Body Composition Obtained by Dual Energy X-Ray Absorptiometry in Preterm and Term Neonates. J Pediatr Gastroenterol Nutr . 1998;27(2):184-190.

9. Dung NQ, Fusch G, Ambrust S, et al. Body composition of preterm infants measured during the first months of life: bioelectrical impedance provides insignificant additional information compared to anthropometry alone. Eur J of Pediatr . 2007;166(3):215-222.

10. Koo WW, Hockman EM, Hammami M. Validation of bone mass and body composition measurements in small subjects with pencil beam dual energy X-ray absorptiometry. J Am Coll Nutr. 2004;23(1):79-84.

11. Ellis KJ. Methods of measuring body composition. In: Thureen PJ \& Hay WW (Eds.), Neonatal Nutrition and Metabolism, (2nd edn), Cambridge University Press, UK. 2006. p. 602-608.

12. Ellis KJ. Evaluation of body composition in neonates and infants. Semin Fetal Neonatal Med. 2007;12(1):87-91.

13. Verma RP, Shibli S, Fang H, et al. Clinical determinants and utility of early postnatal maximum weight loss in fluid management of extremely low birth weight infants. Early Human Dev. 2009;85(1):59-64.

14. Wemhoner A, Ortner D, Tschirch E, et al. Nutrition of preterm infants in relation to bronchopulmonary dysplasia. BMC Pulm Med. 2011;11:7.

15. Lucas A. Long-Term Programming Effects of Early NutritionImplications for the Preterm Infant. J Perinatol . 2005;25(Suppl 2):S2S6.

16. Singhal A, Wells J, Cole TJ, et al. Programming of lean body mass: a link between birth weight, obesity and cardiovascular disease? Am J Clin Nutr . 2003;77(3): 726-730.

17. Morley R. Fetal origins of adult diseases. Semin Fetal Neonatal Med. 2006;11(2):73-78.
18. Ross ES, Krebs NF, Shroyer AL, et al. Early growth faltering in healthy term infants predicts longitudinal growth. Early Hum Dev 2009;85(9):583-588.

19. deRegnier RA, Guilbert TW, Mills MM, et al. Growth failure and altered body composition are established by one month of age in infants with bronchopulmonary dysplasia. J Nutr. 1996; 126(1):168-175.

20. Excler JL, Sann L, Lasne Y, et al. Anthropometric assessment of nutritional status in newborn infants. Discriminative value of mid arm circumference and of skinfold thickness. Early Hum Dev. 1985;11(2):169-178.

21. Koo WW, Walters JC, Hockman EM. Body composition in neonates: relationship between measured and derived anthropometry with dual-energy X-ray absorptiometry measurements. Pediatr Res. 2004;56(5):694-700.

22. Schmelzle HR, Fusch C. Body fat in neonates and young infants: validation of skinfold thickness versus dual-energy X-ray absorptiometr y. Am J Clin Nutri. 2002;76(5):1096-1100.

23. Georgieff MK, Mills MM, Bhatt P. Validation of two scoring systems which assess the degree of physiological instability in critically ill new born infants. Crit Care Med . 1989;17(1):17-21.

24. Gross SJ, David RJ, Bauman L, et al. Nutritional composition of milk produced by mothers delivering preterm. J Pediatr. 1980;96(4):641-644.

25. Sann L, Durand M, Picard J, et al. Arm fat and muscle areas in infancy. Arch Dis Child . 1988;63(3):256-260.

26. Brans YW, Sumners JE, Dweek HS, et al. A non-invasive approach to body composition in the neonate: dynamic skinfold measurements. Pediatr Res . 1974;8(4): 215-222.

27. Gurney JM, Jelliffe DB. Arm anthropometry in nutritional assessment: nomogram for rapid calculation of muscle circumference and crosssectional muscle and fat areas. Am J Clin Nutr. 1973;26(9): 912-915.

28. Thornton CJ, Shannon DL, Hunter MA, et al. Dynamic skinfold thickness measurements: a noninvasive estimate of neonatal extracellular water content. Pediatr Res . 1982;16(12):989-994.

29. Picaud JC, Rigo J, Nyamugabo K, et al. Evaluation of dual energy x-ray absorptiometry for body composition assessment in piglets and term human neonates. Am J Clin Nutr. 1996;63(2): 157-163.

30. Fusch C, Slotboom J, Fuehrer U, et al. Neonatal body-composition: dual-energy X-ray absorptiometry, magnetic resonance imaging, and three-dimensional chemical shift imaging versus chemical analysis in piglets. Pediatr Res. 1999;46(4):465-473.

31. Dung QN, Fusch G, Armbrust S, et al. Body composition of preterm infants measured during the first months of life: bioelectrical impedance provides insignificant additional information compared to anthropometry alone. Eur J Pediatr. 2007;166(3):215-222.

32. Zeigler EE, O'Donnell AM, Nelson SE, et al. Body composition of the reference fetus. Growth. 1976;40(4):329-341.

33. Apte SV, Iyengar L. Composition of human foetus. $\mathrm{Br} J$ Nutr. 1972;27(2):305-312.

34. Bauer K, Versmold H, Prolss A, et al. Estimation of extracellular volume in preterm infants less than $1500 \mathrm{~g}$, children and adults by sucrose dilution. Pediatr Res. 1990;27(3):256-259.

35. Bauer K, Versmold H. Postnatal weight loss in preterm neonates less than $1,500 \mathrm{~g}$ is due to isotonic dehydration of the extracellular volume. Acta Paediatr Scand Suppl . 1989;360:37-42.

36. Hartnoll G, Betremieux P, Modi N. Body water content of extremely preterm infants at birth. Arch Dis Child Fetal Neonatal Ed. 2000;83(1): F56-F59.

37. Shaffer SG, Meade VM. Sodium balance and extracellular volume regulation in very low birth weight infants. J Pediatr. $1989 ; 115(2): 285-290$ 
38. Sulyok E. Physical water compartments: a revised concept of perinatal water physiology Physiol Res. 2006; 55(2): 133-138.

39. Brans YW. Body fluid compartments in neonates weighing 1000 grams or less. Clin Perinatol. 1986;13(2):403-417.

40. Schaffer SG, Quimiro CL, Anderson JV, et al. Postnatal Weight Changes in Low Birth Weight Infants. Pediatrics. 1987;79(5): 702-705.

41. Acra SA, Rollins C. Principles and guidelines for parenteral nutrition in children. Pediatr Ann. 1998;28(2):113-120.
42. Kashyap S, Schulz KF, Forsyth M, et al. Growth, nutrient retention and metabolic response in low birth weight infants fed varying intakes of protein and energy. J Pediatr. 1988;113(4): 713-721.

43. Agostoni C, Buonocore G, Carnielli VP, et al. Enteral Nutrient Supply for Preterm Infants: Commentary From the European Society for Paediatric Gastroenterology, Hepatology, and Nutrition. J Pediatr Gastroenterol Nutr . 2010;50(1):85-91. 